\title{
Biodiesel Technology and Management From Used Cooking Oil in Thailand Rural Areas
}

\author{
Pongsiri Jaruyanon $^{1}$ and Wongkot Wongsapai ${ }^{2}$ \\ ${ }^{1}$ Department of mechanical Engineering, Faculty of Engineering and Industrial Technology, \\ Silpakorn University, Nakorn Prathom, Thailand \\ Phone: +66-81-456-5687 Fax: +66-2-943-9397, e-mail: airypoly@yahoo.com \\ ${ }^{2}$ Department of mechanical Engineering, Faculty of Engineering, \\ Chiang Mai University, Chiang Mai, Thailand. \\ Phone: +66-81-681-2002 Fax: +66-53-892-375, e-mail: wongkot_w@yahoo.com
}

\begin{abstract}
The small-scale demonstrated biodiesel production unit from used cooking oil project have been design and constructed for use in rural areas in Nhong Pling municipality, Nakorn Sawan province, located in the Northern region of Thailand under full government subsidization. In this paper, the used cooking oil potential quantity has been surveyed. From the results, we found that there are 1.3 million litres of used cooking oil per year in Nakorn Sawan. Most are from cooking activities in residential sector and restaurant. The used cooking oil can turn to biodiesel by using transesterification processes which converted triglycerines to biodiesel by mixing it with methanol to be fatty acid methyl esters. Biodiesel can be used for various proposes; e.g. diesel substitution in trucks, agricultural machines, or fuel oil substitution in thermal generation. This paper also discussed the management and flows of biodiesel, from the sources to the end-users.
\end{abstract}

Keywords: Biodiesel technology, Renewable energy, Thailand

\section{Introduction}

As one of ongoing developing countries of Asia, Thailand experienced one of the world's highest economic growth rate with the average annual growth rate (AAGR) of 8.3\% during 1985 to the economic crisis in 1997, and recovered again since 1999 . By the end of 2003, Thailand economic situation was known as the world's second highest in gross domestic product (GDP) growth rate of $6.7 \%$ and the GDP still continuously grows till now.

Considering on the country's final energy consumption, under the $70 \%$ energy imported, transport sector plays a dominant role as more than one-third in shares of total energy consumption every year. The main fuel uses in transport sector, at $72 \%$ of total energy uses in transport sector, is diesel which mainly used in trucks, vans, locomotive, marine transport, and agricultural equipment [1]. This means that if Thailand can domestically produce her own biodiesel unit, which can automatically substitute to the convention biodiesel or can be mixed upto B10, the benefits would widely impact to the country.
The objectives of this study are based on four main problems; i.e. (i) to promote the renewable energy technology and produce biodiesel in rural community, (ii) to reduce the household energy expenses, (iii) to reduce the water hazard from pouring the used cooking oil into the river, and (iv) to reduce the reused of used cooking oil behavior in restaurants which may causes the cancer from dioxin.

This paper is organized in five sections as follows; section 2 postulates the general information of biodiesel followed by the production processes and the biodiesel unit of our study in section 3 and 4, respectively. Section 5 discusses about the management of the biodiesel system under the community based. Finally, section 6 provides some concluding remarks.

\section{Biodiesel: general information}

Biodiesel is a renewable fuel manufactured from cooking oils, artificial fats, and recycled or used cooking oil. It is widely known as diesel substitution in transport sector (automobiles) and agricultural sector (machines). The advantages and disadvantages of biodiesel are as follows;

\subsection{The advantages}

- It is renewable with energy efficient and also displaces petroleum derived diesel fuel,

- It can be used in most diesel equipment and no or only minor modifications,

- It can reduce greenhouse gases emissions and tailpipe emissions, including air toxics and smogs,

- It is domestically production from either agricultural (crude palm oil or jatropha) or recycled resources (used cooking oil),

\subsection{The disadvantages}

- It increases NOx especially in Some kinds of B100,such as those high in polyunsaturated fatty acid, it produce more NOx than B100 high in saturated fatty acids,

- It contains $10 \%$ less calorific value than the conventional diesel, 


\section{The biodiesel production processes}

Even there are various biodiesel production technology, but there are two main technologies widely used in biodiesel production in Thailand; i.e. (i) transesterification technology, and (ii) acid esterification technology. In this study, the biodiesel is produced from the used cooking oil from widely sources, e.g. oil gathering from fresh markets, school canteens, or restaurants. By using the trans-

esterification processes, as shown in equation 1, it converts triglycerides to biodiesel with the temperature of 60 to $70^{\circ} \mathrm{C}$ at atmosphereic pressure. The crude glycerin and crude biodiesel would then separate. The separated crude biodiesel is washed with mildly acidic water to remove the neutralized catalysts, water soluble glycerin, soaps, and methane. For the remaining crude glycerin, it would then refined to various grades according to various purposes.

Used cooking oil + Methanol $\rightarrow$

Methyl esters + Glycerin

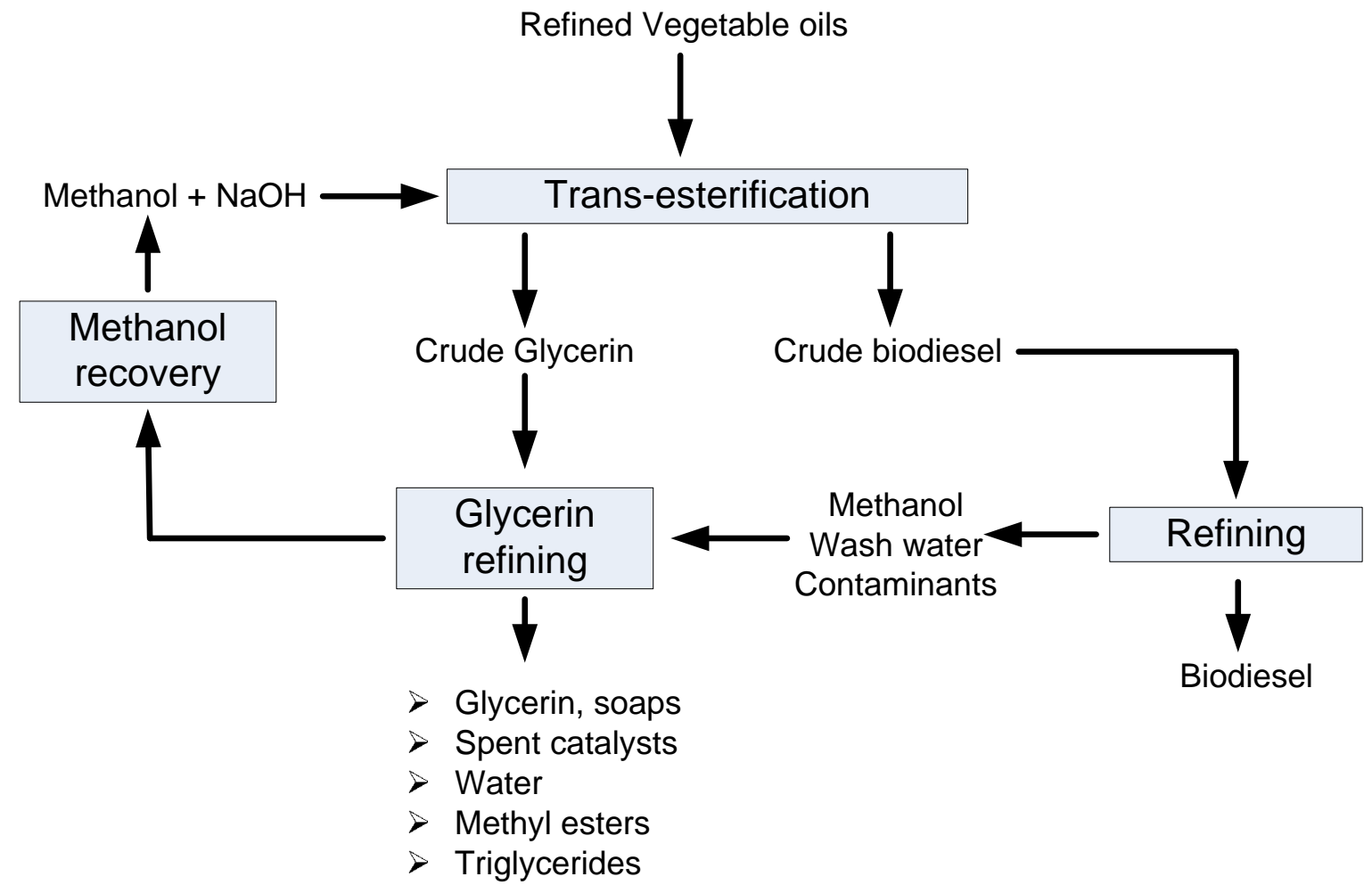

Figure 1 illustrates the trans-esterification technology.

\section{The unit}

The biodiesel unit in our study was designed and constructed based on the trans-esterification technology. The unit schematic diagram illustrates in figure 2. With 150 to 300 litres of biodiesel production per day capacity, this biodiesel unit is appropriately focused on the small-scale community based propose. Figure 3 shows the biodiesel unit operated in Nhong Pling municipality, Nakorn Sawan province. This unit is a prototype biodiesel unit in this province with 150 litres per day production and operates 20 days per month.

As seen in figure 2, the units consists of 11 parts as follows; (1) the reactor tank, (2) water tank,
(3) methanol tank, (4) used cooking oil pump (explosion proved), (5) water pump, (6) chemical pump, (7) heater controller, (8) oil nozzle, (9) used cooking oil filter, (10) biodiesel filter, and (11) electrical control box. The unit shown in this figure 3 costs approximately 2,700 US dollar, with all domestically made [2].

After finish production, the biodiesel then be distributed to the end-users, as seen in figure 4, which mostly are the villagers around the Nhong Pling municipal. This biodiesel can be used in one-stroke small agricultural engines in farm, as seen in figure 5, without any machine adjustment required. 


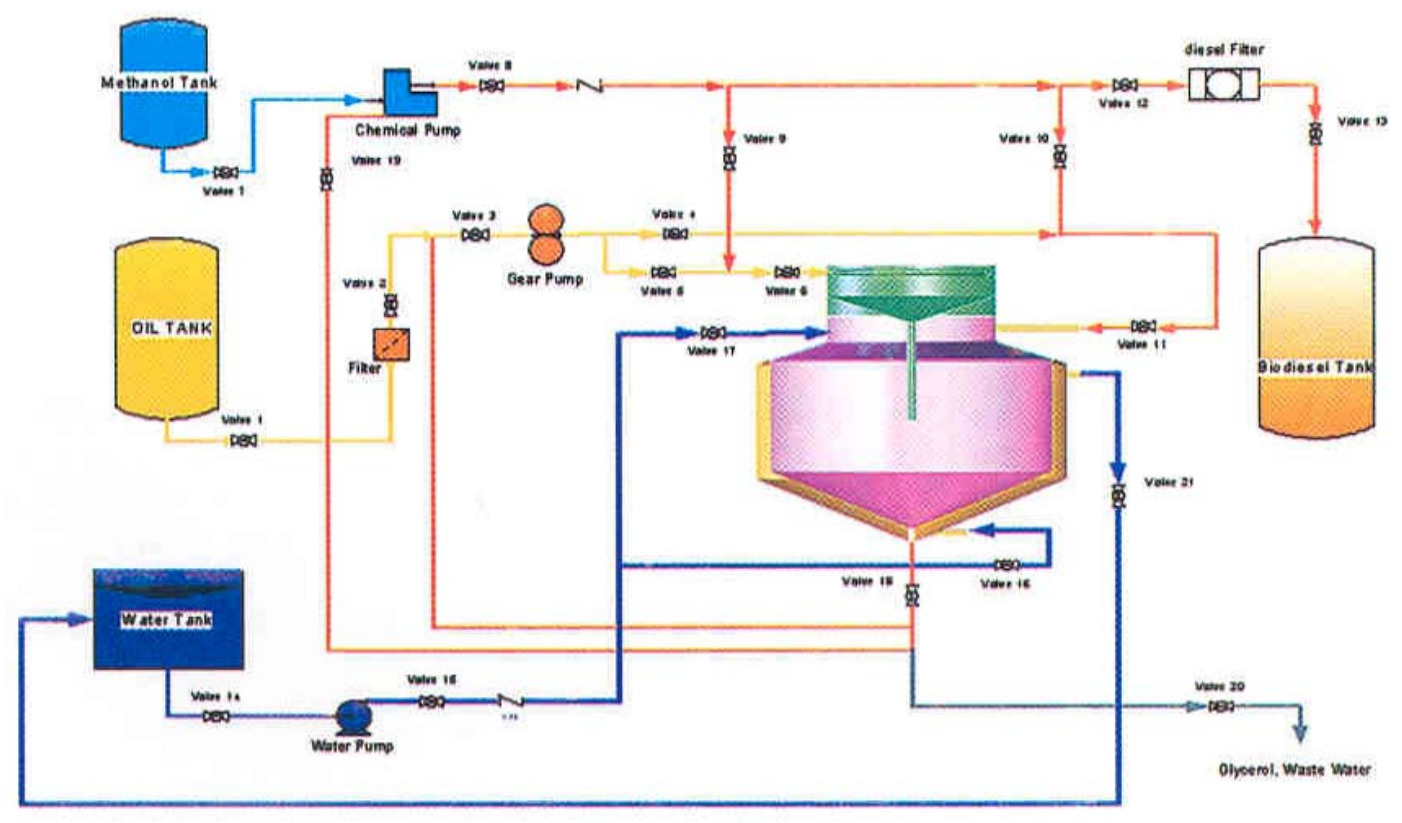

Bio-Dlesel Plant Diagram

Figure 2 Schematic diagrams of biodiesel unit.[2]

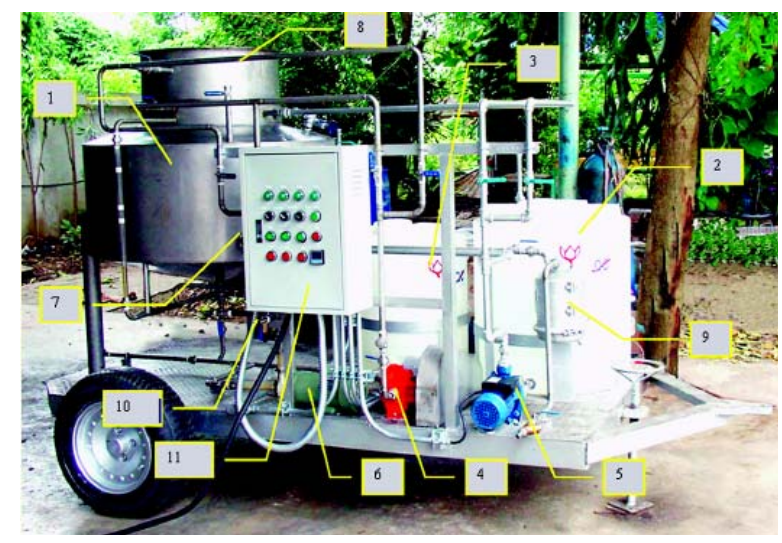

Figure 3 The biodiesel production unit.in Nhong Pling municipality, Nakorn Sawan province.

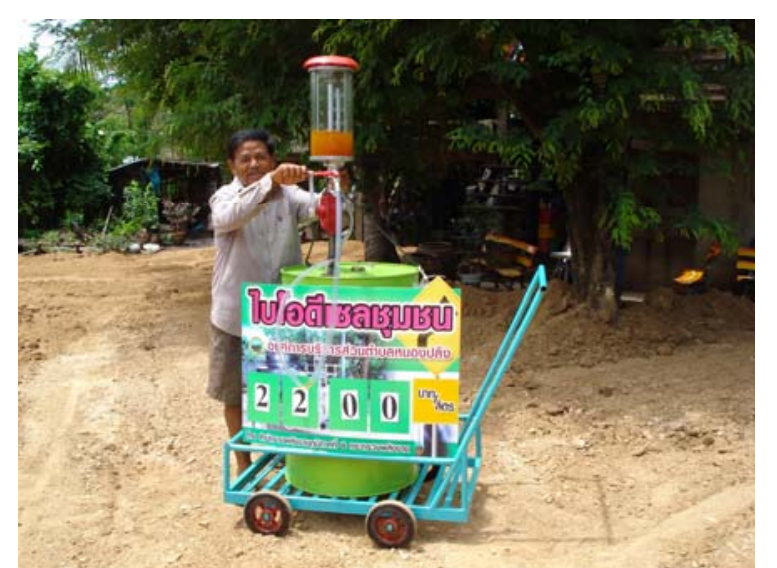

Figure 4 Biodiesel distributing/selling unit.in .in Nhong Pling municipality, Nakorn Sawan province.

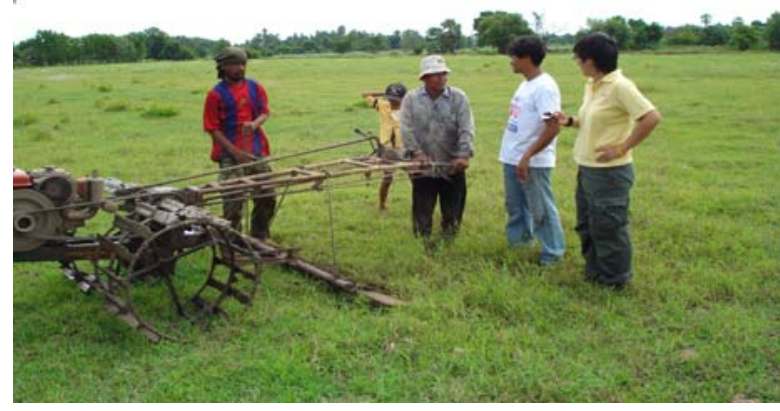

Figure 5 Biodiesel used in one-stroke small agricultural engines.in Nakorn Sawan province.

\section{The management}

For sustainable operation, the management system for biodiesel in the municipal level is strongly required. The executive staff of Nhong Pling municipality have set the biodiesel plan as shown in figure 6. Started with the establishment of biodiesel committees as shown in figure 7 , selected from one person represent for each village in the municipality to develop their management plan to handle their biodiesel unit.

The activities of the committee consists of the survey of supply (used cooking oil in each village) and survey of demand (number of the agricultural machines in each village). They found that there is not sufficient used cooking oil in their municipality for supporting their 3,000 litres per month biodiesel demand. The used cooking oil then needed to import from the markets outside the municipality. 


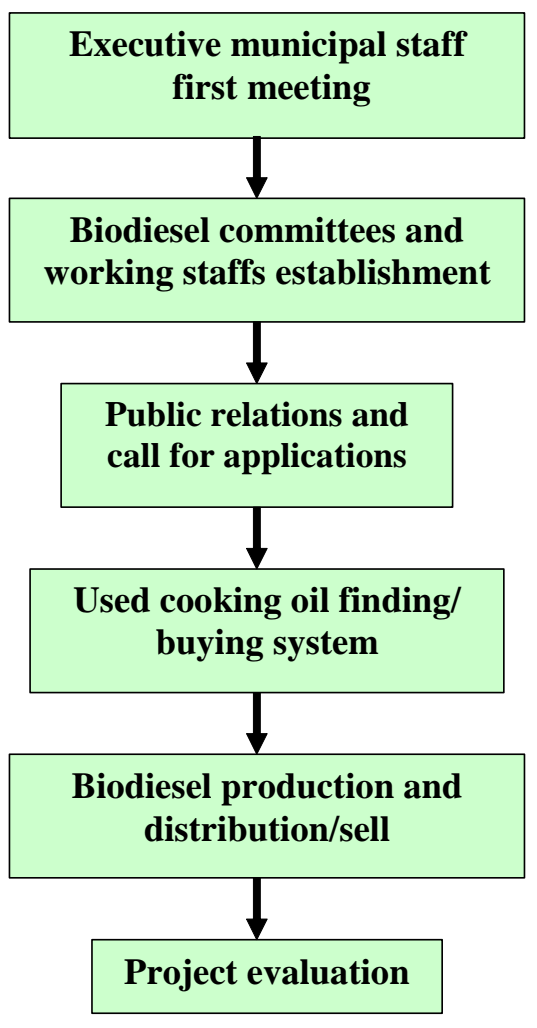

Figure 6 The management of biodiesel project.
In case of municipal level, the Nhong Pling municipality have set full-time staffs to handle the biodiesel unit including the used cooking oil supply, public relations of biodiesel to villagers.

About the selling retail price of biodiesel, the committees have set the price at around 10\% cheaper than convention diesel retail price (in Thai market, the diesel retail price in Nakorn Sawan is around 30 Baht per litre and 1 US dollar equals to 37 Baht at 2007). This policy is set under the subsidization from the municipality, if any.

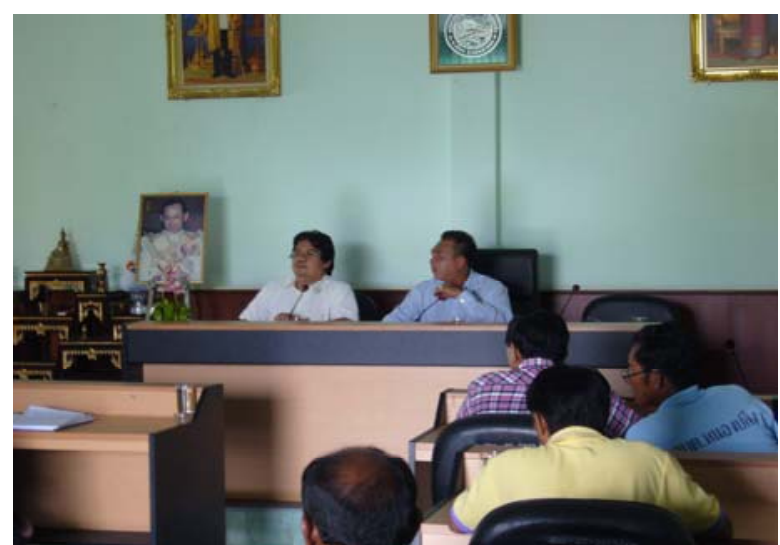

Figure 8 The municipal biodiesel committees during the meeting.

The meeting of the biodiesel committees is set every month as shown in figure 8 .

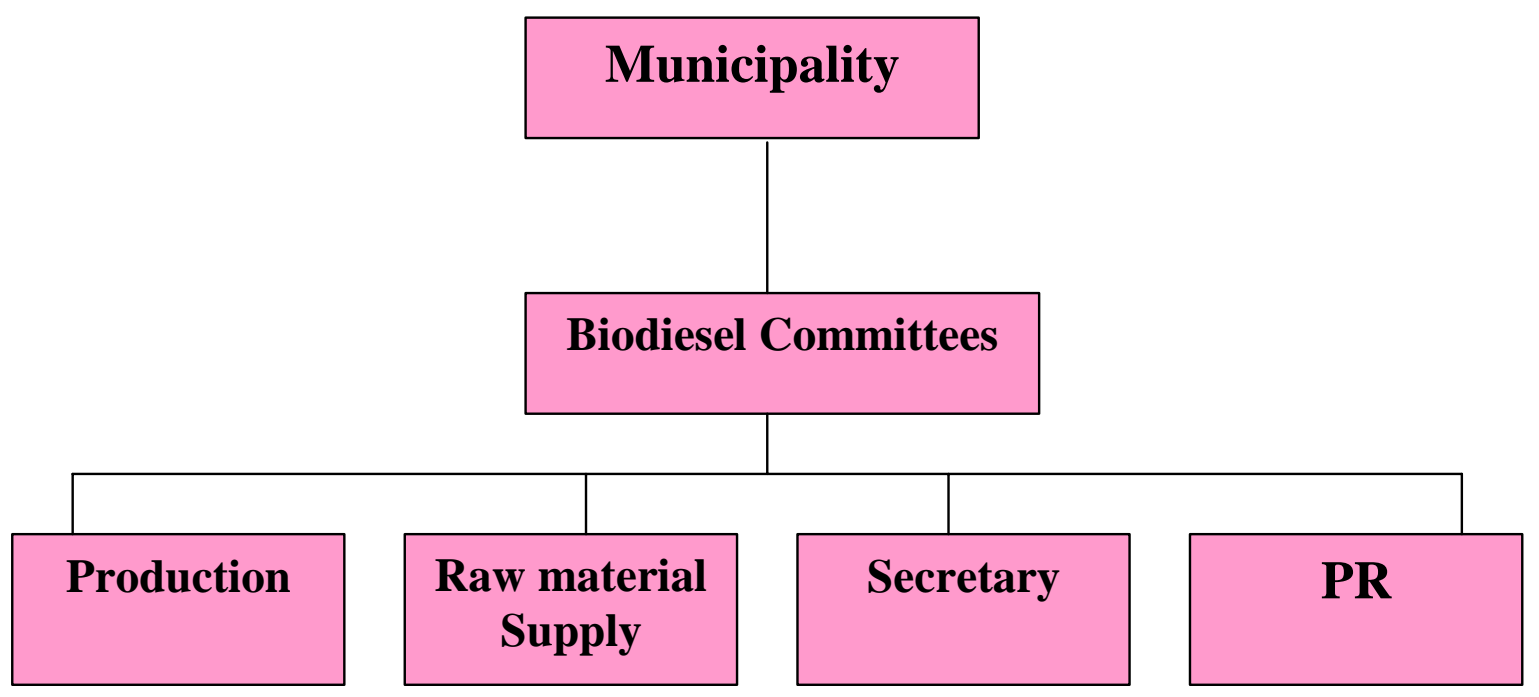

Figure 7 The organization of biodiesel committee [2].

\section{Conclusions}

According to the national renewable energy policy and sustainable development in energy policy, the small-scale demonstrated biodiesel production unit from used cooking oil project have been design and constructed for use in rural areas in Nhong Pling municipality, Nakorn Sawan province, located in the

Northern region of Thailand under full government subsidization. The used cooking oil can turn to biodiesel by using transesterification processes which converted triglycerines to biodiesel by mixing it with methanol to be fatty acid methyl esters. Biodiesel can be used for various proposes; e.g. diesel substitution in trucks, agricultural machines, or fuel oil substitution in thermal generation. The management 
and flows of biodiesel, from the sources to the endusers have also set by the municipal staff to keep this renewable enrgy project sustainable in the long run.

\section{Acknowledgments}

The authors would like to thank the Nakorn Sawan administration province for financial support of the biodiesel project and the Regional Energy Coordination Office 8-Nakorn Sawan Province, especially Mr.Anirut Tanakornmontri, for supporting throughout our works with valuable comments. All participated communities for research and all supports. We remain culpable for any remaining errors.

\section{References}

[1] DEDE (2007), Thailand Energy Situation 2006, Department of Alternative Energy Development and Efficiency, Thailand.

[2] Silpakorn University (2007), The Biodiesel in Nhong Pling Municipality Project, Final report submitted to Ministry of Energy, Thailand. 